\title{
History of Pediatric Dentistry in Nepal
}

\author{
Gajendra Birajee, ${ }^{1}$ Bandana Koirala, ${ }^{2}$ Senchhema Limbu, ${ }^{3}$ Mamta Dali, ${ }^{4}$ Sneha Shrestha ${ }^{5}$ \\ ${ }^{1}$ Assistant Professor, ${ }^{2}$ Professor, ${ }^{3,4}$ Associate Professor, ${ }^{5}$ Assistant Professor \\ 1,2,45 Department of Pedodontics and Preventive Dentistry, College of Dental Surgery, B.P. Koirala Institute of Health Sciences, Dharan, Nepal, \\ ${ }^{3}$ Department of Pedodontics and Preventive Dentistry, Kantipur Dental College and Teaching Hospital, Kathmandu, Nepal.
}

\begin{abstract}
Pediatric dentistry is an age-defined specialty that includes a vast array of oral healthcare-related disciplines for children. It is the most needed health care services and yet the most neglected in Nepal. Specialist pediatric dental practice in Nepal started around two decades ago. The Nepalese Association of Pediatric Dentistry (NAPD) is a nonprofit, non-government, national organization of pediatric dentists of Nepal formed with the motto of uplifting oral health of children throughout the country. NAPD is consistently conducting conferences, workshops, continuing dental education (CDE) programs and symposiums. It also serves community by conducting many free oral health check-ups, and oral health awareness rallies for fulfilling the purpose of maintaining the good oral health of children.
\end{abstract}

Keywords: Association; nepalese; pediatric dentistry.

\section{INTRODUCTION}

Pediatric dentistry is an age-defined specialty that provides both primary and comprehensive preventive and therapeutic oral health care for infants and children through adolescence, including those with special health care needs. ${ }^{1}$ It is a very vast discipline onto itself apart from incorporating a variety of other disciplines, techniques, procedures, and skills that share a common basis with other specialties but are modified and adapted to the unique needs of every child patient. It includes child psychology and behavior guidance, care of the medically and developmentally compromised and special needs patients, supervision of orofacial growth and development, caries prevention, control and treatment, pediatric endodontics, management of emergencies and traumatic injuries, sedation, pharmacological management, hospital dentistry, child abuse and neglect prevention, identification, documentation and reporting,

\section{Correspondence}

Dr. Gajendra Birajee

Assistant Professor, Department of Pedodontics and

Preventive Dentistry, College of Dental Surgery, B.P. Koirala

Institute of Health Sciences, Dharan, Nepal.

E-mail: gajendrabirajee@gmail.com

\section{Citation}

Birajee G, Koirala B, Limbu S, Dali M, Shrestha S. History of Pediatric Dentistry in Nepal. J Nepalese Assoc Pediatr Dent. 2020;1(1):27-31. community oral services for the child population, as well as other traditional fields of dentistry. ${ }^{1}$

Pediatric dentistry is the most needed health care services and yet the most neglected in Nepal. The major factors responsible for this are poverty, lack of education and awareness amongst parents/caretakers regarding the importance of child's oral health, scarcity of dentists in rural areas, lack of knowledge of child psychology and proper behavior guidance skills in general dentists, and extremely low number of pediatric dentists. The dentistpopulation ratio in the capital and major cities is gradually decreasing; which however remains very high in rural areas of Nepal. ${ }^{2}$

\section{PEDIATRIG DENTISTRY IN NEPAL}

The history of dental practice in Nepal dates back to more than a hundred years. It has been nearly 80 years since a qualified dentist started a dental practice in Nepal. ${ }^{3}$ The history of specialist pediatric dental practice in Nepal is around 20 years when Dr. Anuja Ranjitkar was registered as the first Nepalese pediatric dentist in Nepal Medical Council and she started her academic practice from People's Dental College and Hospital back then. Most of the pioneer pediatric dentists studied from India and China. In 2006, Kathmandu University, Dhulikhel started faculty developmental program by tying a knot with 


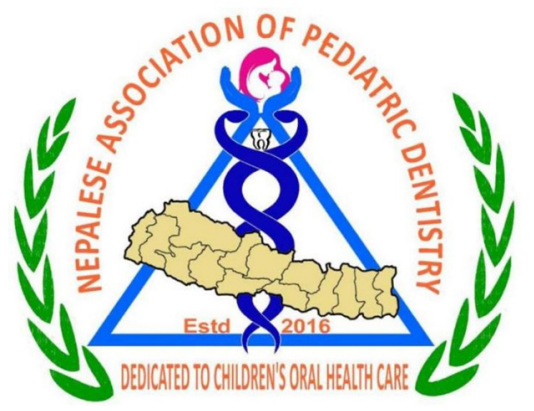

Figure 1. The logo of NAPD.

Manipal Academy of Higher Education, Karnataka, India from where 12 pedodontists graduated. From 2011 B.P. Koirala Institute of Health Sciences (BPKIHS), Dharan started postgraduates programme in Nepal and every year two postgraduates got the opportunity to be guided by Professor Dr. Bandana Koirala. In 2018 Tribhuvan University started postgraduation in Pedodontics (one PG seat) from People's Dental College and Hospital, Kathmandu. From this year 2020, Kathmandu University will begin the residency program through Kantipur Dental College and Hospital and Kathmandu University School of Medical Sciences Dhulikhel with one postgraduate seat in each school. In addition, CODS, BPKIHS, Dharan got an expansion of one more postgraduate seat from the year 2020. With these additions, we see a rise in the number of residents from an initial 2 to 6 every year from 2020 onwards. This addition is believed to help students who wish to pursue a specialization in this field as well as filling the huge gap of pediatric dentists to child population ratio.

In Nepal, the population of children under the age of 15 years old is estimated to be approximately 10,392,358 at the beginning of $2020 .{ }^{4}$ Due to an extremely less number of pediatric dentists (around 28), the pediatric dentists to children population ratio is exceptionally low $(1: 371,156)$ in our country.

\section{NEPALESE ASSOCIATION OF PEDIATRIC DENTISTRY}

Nepalese Association of Pediatric Dentistry (NAPD) is a nonprofit, non-government, national organization of pediatric dentists of Nepal established on 3rd Jestha 2073 B.S. (16th May 2016 A.D.). NAPD is primarily concerned to uplift the areas of practice, education, and research related to the field of pediatric dentistry. It aims to improve the status of oral health in children of Nepal and encourages clinical care to be as accessible as possible throughout the nation. It believes in sharing the academic knowledge and clinical skills being learned among its members along with other health care professionals thus helping to improve the overall standard of oral health care in infants, children, adolescence, and persons with special needs. NAPD additionally prefers to work together with other public and global oral and pediatric healthcare-related associations and societies to develop a multidisciplinary professional attitude and has performed various works for the upliftment and awareness in child oral health care.

The logo of NAPD was made incorporating many components. A triangle at the core of the logo represents the pedodontic treatment triangle. Inside the triangle is the Rod of Asclepius which symbolizes healing in the health care fields. A mother cradling her child at the top signifies the protection and fundamental rights of every child to their total oral health care. A map of Nepal in the center of the logo represents the sincere responsibilities of the members of NAPD towards maintaining the good oral health of children throughout the country (Figure 1). ${ }^{5}$ NAPD was formed following the constitutional laws of the country and had 9 founder members: President-Dr. Bandana Koirala, Vice President-Dr. Sunanda Sundas, General Secretary-Dr. Senchhema Limbu, Joint SecretaryDr. Parajeeta Dikhshit, Treasurer-Dr. Sanskriti Khanal and Members-Dr. Mamta Dali, Dr. Sumita Upadhya, Dr. Megha Pradhan and Dr. Sneedha Mainali.

\section{PEDIATRIC DENTISTS NUMBER IN NEPAL}

Currently, around 28 pediatric dentists are practicing in Nepal with Nepal Medical Council Registration. There are a total of 26 members in NAPD of which 24 Nepalese pediatric dentist are life members and 2 are gold members 


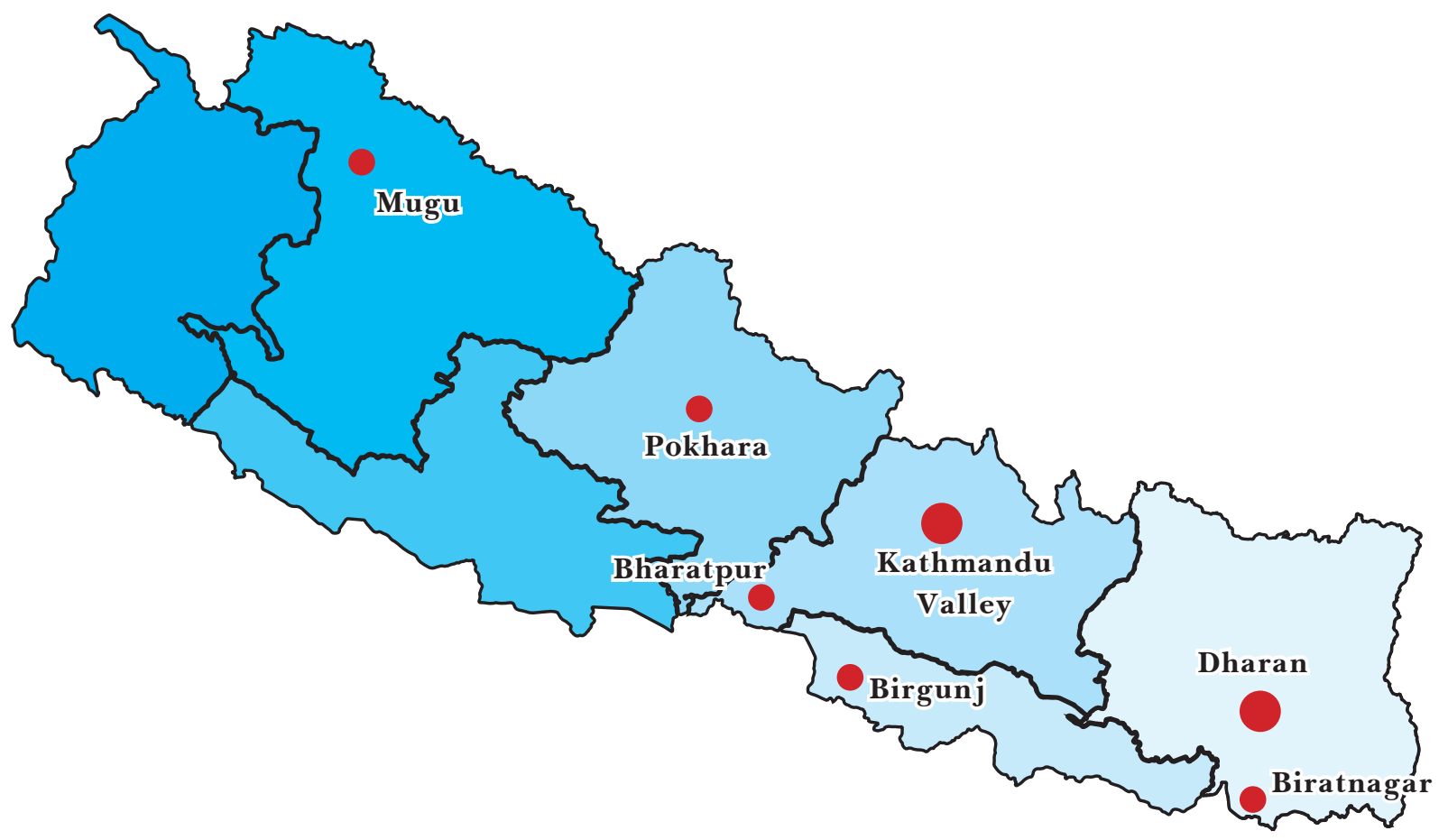

Figure 2. Pediatric dentist's population in the major cities of Nepal. The size of the circle represents the number of pediatric dentists.

which is given to foreign national pediatric dentist who wishes to be a member of NAPD. ${ }^{6}$ Most of the pediatric dentists in Nepal are employed as faculties in dental and medical colleges across the country. Few are working as consultant pediatric dentists in government and private hospitals and clinics in major cities (Figure 2). Most of the part of Nepal does not even have a single pediatric dentist due to lesser number of them, geographic factors and inaccessibility of health posts in the rural areas leading to unavailability of dental health care to the needy children.

\section{ACHIEVEMENTS OF NEPALESE PEDIATRIC DENTISTRY}

Nepalese pediatric dentistry has been flourishing through pedodontists working in various colleges around the country who have reached out and served pediatric dental population and special needs children of their respective areas in this two decades period of time. Some of the works done by them are:

A workshop on "Nitrous Oxide-Oxygen Inhalation Sedation (NOIS) in dental practice" was organized by the Department of Pedodontics and Preventive Dentistry, CODS, BPKIHS from 24th to 25th September in 2014 under the veteran course faculty Prof. Dr. Srinivas
Namineni from India. Thereafter, a research entitled "Assessment of dental fear and anxiety using nitrous oxideoxygen inhalation sedation in children visiting BPKIHS" was conducted in CODS, BPKIHS between October 2015 - September 2016. The study showed a significant reduction in Dental Fear and Anxiety (DFA) in children after treatment under NOIS and was effective to reduce DFA in both invasive and non-invasive dental treatment. NOIS also helped children to show positive behavior during invasive and non-invasive dental treatment.

\section{ACHIEVEMENTS THROUGH NAPD}

After NAPD formation, in 2017 it became a member of the International Association of Pediatric Dentistry (IAPD) and on World Oral Health Day/20th March oral health promotion rally was conducted with a free oral health check-up for a month all over Nepal (2017 and 2018). The first conference of NAPD, the PEDO-GENESIS (Comprehensive Pediatric Dentistry) was held on 8th April 2017 at Hotel Shangri-La, Kathmandu with distinguished Invited speakers and National speakers who included the President and other executives from the Indian Society of Pedodontics and Preventive Dentistry (ISPPD). In conjugation with Nepal Dental Association (NDA) and Nepal Critical Care Development Foundation, a 3-day 
workshop was conducted on Basic Life Support (BLS) and conscious sedation by NOIS from 2nd to 4th June 2017 at KIST Medical College, Kathmandu. NAPD collaborated with Nepal Dental Association in 2nd international NDA conference in November 2017. NAPD alongside the Orthodontic and Dentofacial Orthopedic Association of Nepal conducted a CDE program on Interceptive Orthodontics in December 2017.

The second annual conference, the PEDONEP (Nurture the Future) was held from 4th-6th April 2018 at BPKIHS, Dharan. ${ }^{7}$ Pre-conference workshop on Zirconia Crown and BLS were conducted on 4th April 2018. The Kids-e crown company conducted Zirconia crown workshop and introduced their pediatric anterior aesthetic Zirconia crown in Nepal. The 3 days conference welcomed famous speakers from India and Italy too. In April 2018 NAPD collaborated with the Nepalese Society of Oral Implantology and together led the 1st Conference on Oral Implant in Kathmandu. NAPD took active participation in Nepal Medical Council program for implementing CPD points in Nepal in April 2018. NAPD representative members participated in the first Biennial Conference of South Asian Association of Pediatric Dentistry (SAAPD) held from 4th to 6th May 2018 in New Delhi and decided to conduct SAAPD conference next time in Nepal.

Thus, the third annual conference of NAPD was held in a joint effort with the 2nd congress of SAAPD from 4th to 6th April 2019 at Kathmandu University School of Medical Sciences, Dhulikhel, and Hotel Radisson, Kathmandu. ${ }^{8}$ The 3-day conference included a series of preconference workshops on Edelweiss Pediatric Crown, Functional Jaw Orthopedics, Limited Corrective Orthodontics, Microscopic Endodontics and Crowns, LASER, and Rotatory Endodontics in pediatric dentistry by national and international mentors. The President and the General Secretary of IAPD, the past President of the International Association for Disability and Oral Health and other celebrated global speakers from Dubai, Japan, Russia, Saudi Arabia, South Asia, South Korea, Taiwan, and Ukraine enthusiastically shared their knowledge and skills in this huge conference where the world came united in Nepal.

A symposium on "Interceptive orthodontics for pediatric dentists" was conducted at Kantipur Dental College,
Kathmandu on 8th July 2019. A CDE program on Pulp therapy of primary and young permanent teeth by Dr Matthew S Fisher was held on 8th November 2019. The fourth annual conference of NAPD was expected to be held from 25th to 26th April 2020 which is postponed due to COVID-19. With support from Dr. Matthew Fischer, NAPD members actively participated in the IAPD20 Virtual Conference held from 13th to 17th September 2020 and some Pedodontists presented and reach globally. NAPD members participated in COVDENT 2020 organized by SAAPD from 25th to 27th September where Nepalese Pediatric Dentists were moderators for some sessions. NAPD recently launched its website "www.napd. org.np" in September 2020. Finally, NAPD is stepping forward with the most awaited official publication, the Journal of Nepalese Association of Pediatric Dentistry.

\section{PEDIATRIC ORAL HEALTH SCENARIO IN NEPAL}

The Constitution of Nepal, 2015 has provided a remarkable space to the issues of child rights. There are specific provisions for the rights of children to justice, education, and health care. The role of a pediatric dentist is very important to improve the oral health status of children. The majority of Nepalese children have untreated dental caries. According to a study, 58.2\% of children experienced dental caries with 93.6\% untreated dental caries between the ages of 6 months to 6 years. The number of carious teeth ranged from 0 to 19 , with a mean of 3 decayed teeth. Approximately $19.6 \%$ of children had deep caries into or near the pulp, and $20.0 \%$ of children experienced dental pain. ${ }^{9}$ Likewise, the national oral health policy 2060 B.S. reported the caries prevalence and mean deft of 5-6 years old is $67 \%$ and 3.3 respectively (urban 64\% and 2.9; rural $78 \%$ and 4.0). The caries prevalence and mean DMFT score of $12-13$ years old is $41 \%$ and 1.1 respectively (urban $35 \%$ and 0.9 ; rural $54 \%$ and 1.5). A comparison of data over the last 20 years shows an increasing trend of untreated dental caries. The main causes of dental caries in Nepalese children include increasing sugar consumption, lack of dental fluoridation, malnutrition and poverty. ${ }^{10}$

\section{CONCLUSION}

The journey of pediatric dentistry in Nepal is going on by the enthusiastic Pediatric dentists along with NAPD and has got a lot of accomplishments by effectively leading numerous conferences, workshops, continuing dental 
education (CDE) programs, symposiums, free oral health check-ups and oral health awareness rallies. These are just a few feathers added to the cap of Nepalese pediatric dentistry and we still have a long way to go. NAPD expects to work for the holistic upliftment of child oral health and serve as stakeholders in the national policy and guideline makings for the welfare of child abiding by the highest standard code of ethics. As of now with the journey lead so far, the future seems promising.

\section{Conflict of Interest: None}

JNAPD

\section{REFERENCES}

1. Overview-AAPD. American Academy of Pediatric Dentistry. Reference Manual. 38(6), 2-3. Retrieved 11 November 2020. Available from: https://www.aapd.org/ assets/1/7/Intro12.PDF. [Full Text]

2. Shrestha RM, Shrestha SS, Kunwar N. Dentists in Nepal: A Situation Analysis. J Nepal Health Res Counc. 2017 Sep 8;15(2):187-192. [PubMed I DOI]

Shrestha RM. Thirty glorious years of Nepal dental association. J Nepal Dent Assoc. 2020 Jul-Dec;20(31):60-2. [Full Text]

Retrieved 11 November 2020. Available from: https:/www.countrymeters.info/en/Nepal. [Link]

Nepalese Association of Pediatric Dentistry. About Us. Retrieved 2 October 2020. Available from: https://www.napd.org.np. [Link]

Nepalese Association of Pediatric Dentistry. Members Area. Retrieved 2 October 2020. Available from: https://www.napd.org.np. [Link]

7. 2nd National Conference of Nepalese Association of Pediatric Dentistry 2018. Retrieved 16 September 2020. Available from: https://www. napd2018.blogspot.com. [Link]

8. 2nd Biennial Conference 2019. Retrieved 16 September 2020. Available from: http://www.saapd.asia/2nd-biennial-conference-2018. [Link]

9. Tsang C, Sokal-Gutierrez K, Patel P, Lewis B, Huang D, Ronsin K, Baral A, Bhatta A, Khadka N, Barkan H, Gurung S. Early Childhood Oral Health and Nutrition in Urban and Rural Nepal. Int J Environ Res Public Health. 2019 Jul 10;16(14):2456. [PubMed I DOI]

10. National oral health policy. Retrieved 2 October 2020. Available from: https://www.mohp.gov.np. [Full Text] 